cancer incidence through dietary factors. In a compelling second article, Mitchell and Armstrong outline five guidelines for diet and exercise that will minimise cancer risk. Increasing consumption of vegetables and fruit is the most significant way this can be achieved, and thus cancer prevention alone is sufficient reason for renewed and substantial public health nutrition initiatives.

The third article, by Vita, Moxon and Macoun, argues that there is now a real opportunity for concerted action to promote vegetable and fruit consumption. To guide effective public health action we have in place sound policy frameworks at a national level (Eat Well Australia, 2000-2010) and at a state level (Eat Well NSW, 2001-2005).

The imperatives for cancer prevention, and the additional salience this gives to nutrition messages, provides a strong rationale for collaborative action to improve nutrition across the population. In diet and cancer, as well as other areas of cancer prevention, the key challenge remains one of taking action-of applying what we know and putting it into practice.

\title{
MEASURING RISK FACTORS THAT CAN BE MODIFIED TO PREVENT CANCER
}

\author{
Helen Moore and Louisa Jorm \\ Epidemiology and Surveillance Branch \\ NSW Department of Health

\section{Philip Vita} \\ Health Promotion Branch \\ NSW Department of Health
}

Cancer is a diverse group of diseases characterised by the proliferation and spread of abnormal cells. Different forms of cancer can share common risk factors; however, often a unique set of risk factors are responsible for the onset of a particular cancer. ${ }^{1}$ Risk factors for cancer are both inherent, such as the inherited APC gene that predisposes individuals to develop colorectal cancers; and environmental, such as excessive sun exposure, particularly in childhood, which increases the risk of developing melanoma. Some risk factors are, theoretically at least, easier to modify than others (for example, quitting smoking as compared with inheriting the APC gene). This article deals with measuring the population prevalence of risk factors for which exposure can be modified to prevent the development of cancers.

Health promotion interventions, designed to reduce exposure to these risk factors, can be targeted at:

- individuals, by encouraging healthy lifestyles;

- health services, by ensuring the availability and effectiveness of preventive services;

- healthy environments, by ensuring that the physical, economic, social and political environment supports health. ${ }^{2}$

The following information is summarised from The Health of the People of New South Wales: Report of the Chief Health Officer, 2000. ${ }^{3}$ It represents the key population health indicators of modifiable cancer risk factors, including:
- physical activity

- nutrition

- sun exposure

- exposure to tobacco smoke

- alcohol consumption.

These indicators are intermediate measures of the effectiveness of a range of health promotion interventions aimed at encouraging healthy lifestyles, and establishing effective preventive health services and healthy environments. The details of the methods used to analyse and present data reported can be found in the Report. ${ }^{3}$

\section{PHYSICAL ACTIVITY}

Physical inactivity has been estimated to contribute almost seven per cent to the total burden of disease in Australia, and in this regard it is second only to smoking. ${ }^{4}$ There is substantial evidence that physical activity can protect the large bowel against the development of cancer of the colon and of precancerous polyps, and some evidence that physical activity has a protective effect against breast cancer, particularly in younger women. ${ }^{5}$

Active Australia recommends that every adult in NSW should accumulate at least 30 minutes of moderate-intensity physical activity on most days of the week to confer a general health benefit. ${ }^{6}$ Whether this level of activity, or a greater level, is sufficient to prevent some cancers remains controversial (see article by Mitchell and Armstrong in this issue). The results of the 1997 NSW Health Survey indicated that in 1997, 67 per cent of men and 46 per cent of women expended enough energy on leisure time physical activity to gain a health benefit. This represents an apparent increase in physical activity levels from 1996, when 59 per cent of men and 42 per cent of women reported adequate levels of energy expenditure. 
Figure 1 shows the rates of 'adequate' physical activity in NSW by health area and sex (a definition of 'adequate' accompanies the figure). In men, rates of adequate physical activity ranged from 61 per cent in Western Sydney Area Health Service to 75 per cent in Central Coast Area Health Service. Among women of the same age, rates of adequate physical activity varied from 39 per cent in South Western Sydney Area Health Service to 57 per cent in Mid North Coast Area Health Service. Inadequate levels of physical activity are more prevalent among NSW adults who are married (rather than single), have not finished high school, live in urban areas or economically disadvantaged areas, or who speak a language other than English at home.?

\section{NUTRITION AND FOOD HABITS}

Diet is linked to a variety of cancers including colorectal and prostate cancers. ${ }^{8}$ Eating adequate amounts of foods such as fruit, vegetables and fibre may be protective, while excessive amounts of other foods, such as fats, may be harmful. Figure 2 presents data on a range of dietary indicators from the 1997 and 1998 NSW Health Surveys. NHMRC guidelines recommend that diets should include

\section{FIGURE 1}

ADEQUATE PHYSICAL ACTIVITY BY HEALTH AREA AND SEX, PERSONS AGED 16YEARS AND OVER, NSW, 1997

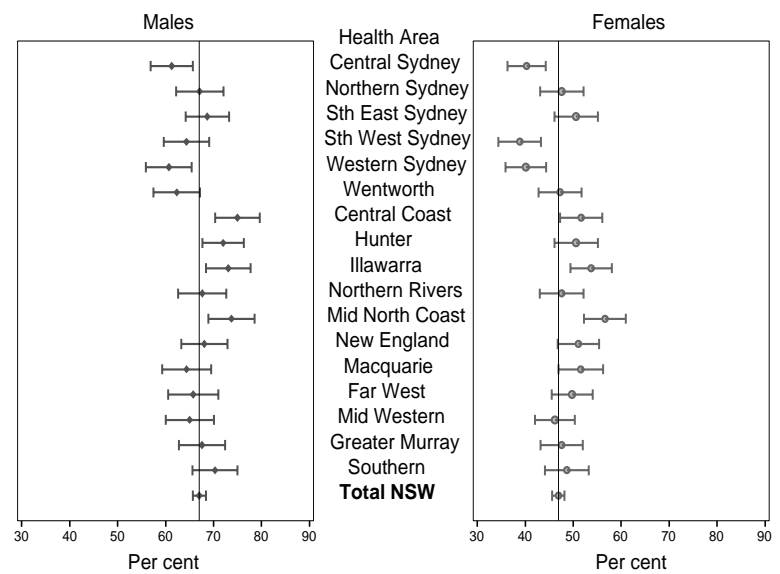

Note: Classification of energy expenditure: 'sedentary' 0-100 kCal/fortnight, 'low' 100-1600 kCal/fortnight, 'medium' $1600-3200 \mathrm{kCal} /$ fortnight or $1600 \mathrm{kCal} / \mathrm{fortnight}$ but did not engage in at least two hours of vigorous activity, 'high' >1600 kCal/fortnight and participated in at least two hours of vigorous activity. 'Adequate' physical activity is 'medium' or 'high' energy expenditure. LL/UL95\% Cl = lower-upper limits of 95 per cent confidence interval for the point estimate.

Source: 1997 NSW Health Survey (HOIST). Epidemiology and Surveillance Branch, NSW Department of Health.

\section{FIGURE 2}

USUAL FOOD INTAKE BY SEX, PERSONS AGED 16 YEARS AND OVER, NSW, 1997 AND 1998

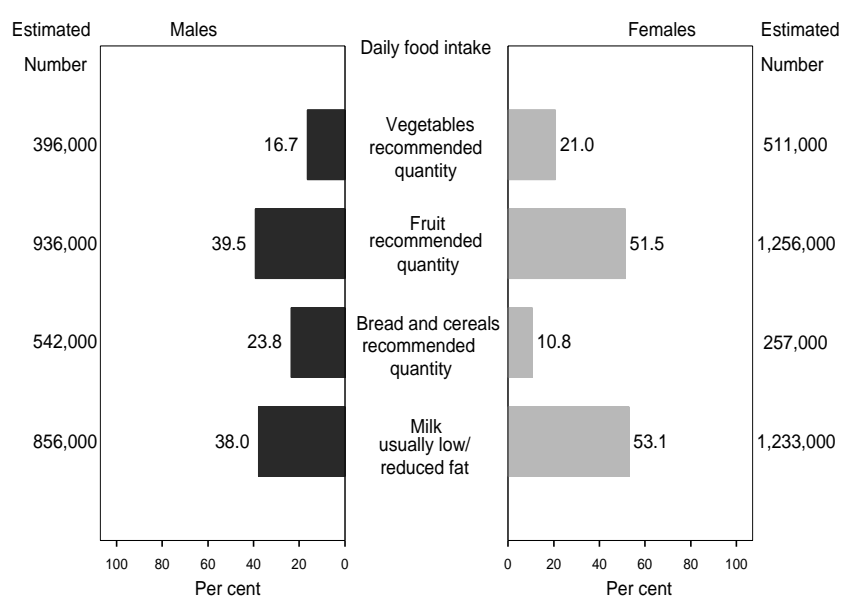

Note: Recommended daily quantity of fruit=300 grams or more. Recommended daily quantity of vegetables $=300$ grams or more. Recommended daily quantity of bread and cereal=210 grams or more. (NHMRC, 1995).

Source: NSW Health Surveys 1997 and 1998 (HOIST). Epidemiology and Surveillance Branch, NSW Department of Health. 
plenty of breads and cereals (preferably wholegrain), vegetables (including legumes) and fruits. ${ }^{9}$

In NSW in 1997 and 1998, only 17 per cent of men ate the recommended quantity of vegetables, and 40 per cent ate the recommended quantity of fruit. Women ate more of these foods, with 21 per cent and 52 per cent reporting eating adequate amounts of vegetables and fruit respectively. In contrast, men ( 24 per cent) were more likely to report eating the recommended quantity of bread and cereals than women (11 per cent).

Milk is a major dietary source of saturated fat as well as an excellent source of calcium. Encouragingly, consumption of low- and reduced-fat milks appears to have increased. In NSW in 1997 and 1998, 38 per cent of men and 53 per cent of women reported usually or always using these milks. This compares with 33 and 46 per cent for men and women respectively in $1994 .^{10}$

\section{SUN EXPOSURE}

Australia has the highest rate of skin cancer in the world. Most skin cancer is caused by unprotected exposure to the sun and most sun-related skin damage occurs in the early years of life. Living in Australia during the first 15 years of life contributes about two-thirds to the risk of melanoma of a lifelong resident. ${ }^{11}$

Figure 3 shows that at the 1997 and 1998 NSW Health Surveys, women were much more likely than men to report usually or always using sunscreen, staying in the shade or avoiding being in the sun between 11.00 a.m. to 3.00 p.m. Men were more likely to report wearing protective clothing or a hat. Comparisons between the 1994 NSW Health Promotion Survey and the 1997 and 1998 NSW Health Surveys should be made with caution due to variations in the questions used and the timing of the surveys. Encouragingly, however, there was a substantial increase in the 1997 and 1998 surveys in the proportion of both males and females who reported staying out of the sun between 11.00 a.m. and 3.00 p.m.

\section{EXPOSURETOTOBACCO SMOKE}

Tobacco smoking is the risk factor causing the greatest burden of disease in Australia. It is responsible for about 12 per cent of the total burden of disease in males and seven per cent in females. ${ }^{4}$ Tobacco smoking was a significant cause of six of the 20 most common types of cancer diagnosed or causing death in NSW in 1997. These were cancers of the lung, bladder, pancreas, stomach, kidney and oesophagus. ${ }^{12}$

Most tobacco users begin, develop and establish their behaviour during adolescence, so preventing smoking in this group is key to reducing tobacco-related illness and death in the long-term. In 1996, among NSW secondary school students aged 12-17 years, 19 per cent of boys and 21 per cent of girls reported having smoked during the previous week. ${ }^{13}$ The prevalence of current smoking increased with age among both sexes, peaking at 27 and 30 per cent among boys and girls, respectively. In 1996, at all ages after 13 years, the prevalence of current smoking among girls exceeded that among boys. ${ }^{3}$

Among adults in NSW in 1997 and 1998, 26.8 per cent of men and 21.4 per cent of women reported current tobacco

\section{FIGURE 3}

SUN PROTECTION BEHAVIOUR BY SEX, PERSONS AGED 18 YEARS AND OVER, NSW, 1994, 1997 AND 1998

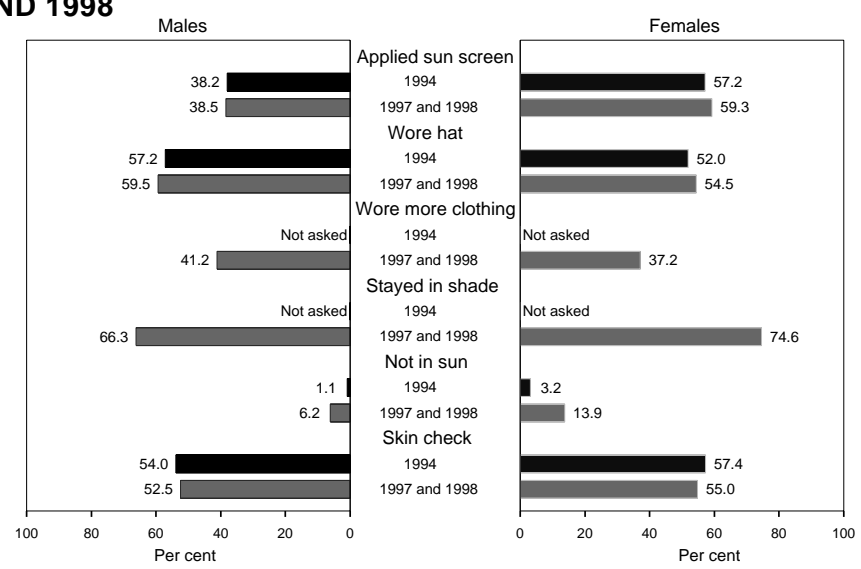

Note: All responses refer to usual behaviours from the pre-survey summer between the hours of 11.00 a.m. and 3.00 p.m. The survey defined: 'Sun Screen' as when a broad spectrum $15^{+}$sunscreen (no less) was applied to at least half of all exposed skin; 'Wore protective clothing' as wore more clothing to protect yourself from the sun; 'Wore a Hat' as wearing a wide-brimmed hat or cap with a flap; 'Skin check-past 12 months' as deliberately checking the skin for changes during the past 12 months. 'Not asked' refers to questions not asked or not asked in a comparable format.

Source: NSW Health Surveys 1997 and 1998, NSW Health Promotion Survey 1994 (HOIST). Epidemiology and Surveillance Branch, NSW Department of Health. 


\section{FIGURE 4}

\section{CURRENT SMOKING BY SOCIEOECONOMIC DISADVANTAGE SCORE FOR POSTCODE OF}

RESIDENCE AND SEX, NSW, 1997 AND 1998
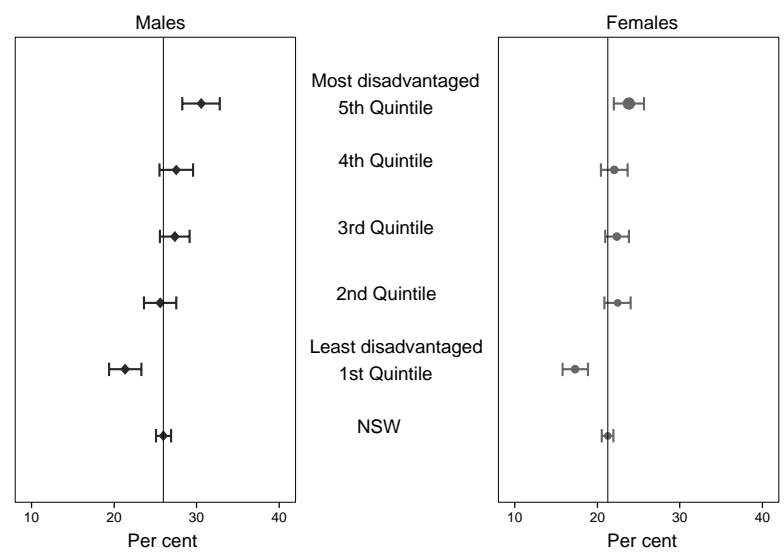

Note: Current smoking includes daily or occasional smoking. Postcode areas were classified into quintiles by scores based on the ABS Index of Relative Socioeconomic Disadvantage (IRSD). LL/UL95\%Cl = lower and upper limits of the 95 per cent confidence interval for the point estimate.

Source: NSW Health Surveys 1997 and 1998, ABS census data and SEIFA index (HOIST), Epidemiology and Surveillance Branch, NSW Department of Health.

smoking. Data on smoking from recent population surveys suggest that smoking rates in NSW have declined by around four per cent among both men and women since 1989-90, but has levelled out in recent years.

In NSW in 1997 and 1998, reported current smoking rates varied widely among health areas. In men, the rates for current smoking varied from 21 per cent in the Northern Sydney Area Health Service to 35 per cent in the Far West Area Health Service. In women, these rates ranged from 17 per cent in the Northern Sydney Area Health Service to 26 per cent in the Central Coast Area Health Service. Variations in smoking rates among health areas reflect the distribution of underlying social determinants of health. They also reflect the differential effect among socioeconomic groups of influences such as health publicity and changes in cigarette price. ${ }^{14}$ Figure 4 shows that there was a strong association between the likelihood of a man or a woman currently smoking in 1997 and 1998 in NSW and increasing socioeconomic disadvantage. The proportion of males currently smoking was greater than the proportion of female smokers in each quintile.

Some of the socioeconomic differences may be explained by variations in smoking rates by indigenous status and country of birth. In the NSW Health Surveys, 41.0 per cent of indigenous people aged 16 years and over reported smoking on a daily or occasional basis. This was 17.2 per cent higher than in the non-indigenous population. ${ }^{3}$ Reported rates of current smoking by country of birth show that in men, rates ranged from 17.5 per cent among the Italian-born, to 43.6 per cent among the Vietnameseborn. In women, current smoking rates ranged from less than one per cent among women born in China and Vietnam, to 35.5 per cent among the New Zealand-born. ${ }^{3}$

\section{ALCOHOL}

Harm caused by alcohol consumption accounts for 4.9 per cent of the total disease burden in Australia. ${ }^{4}$ Excessive alcohol use contributes to many causes of death and illness, including cancers of the liver, mouth, throat, oesophagus and female breast. ${ }^{12}$

In the 1997 and 1998 NSW Health Surveys, more women (30 per cent) than men (16 per cent) reported that they did not drink any alcohol. However, similar proportions of men (19 per cent) and women (20 per cent) reported drinking at hazardous or harmful levels. In men, rates of hazardous or harmful alcohol use varied from 15 per cent in the Northern Sydney Area Health Service to 32 per cent in the Far West Area Health Service. In women, rates of hazardous or harmful alcohol use ranged from 17 per cent in the South Western Sydney Area Health Service to 25 per cent in the Far West Area Health Service. The reported rates in the indigenous population were higher, with 28.2 per cent of indigenous people reporting alcohol consumption at a hazardous or harmful level. The most socioeconomically disadvantaged men and women were more likely to consume alcohol at hazardous or harmful levels than those in less disadvantaged groups. This was particularly shown for men compared to women.

Figure 5 shows that, at the 1997 and 1998 NSW Health Surveys, NSW residents born in many overseas countries were less likely than the Australian-born to report hazardous or harmful alcohol consumption. Among men, reported rates of hazardous or harmful alcohol consumption ranged from less than two per cent among the Chinese-born, to 27.7 per cent among the New Zealand-born. Among women, rates ranged from one per 


\section{HARMFUL OR HAZARDOUS ALCOHOL CONSUMPTION BY COUNTRY OF BIRTH AND SEX, PERSONS AGED 16 YEARS AND OVER, NSW, 1997 AND 1998}
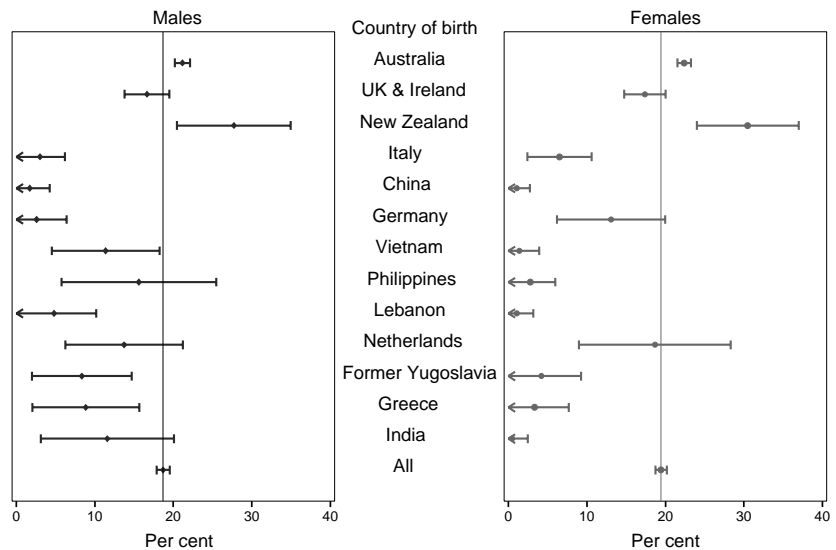

Note: Respondents were asked: 'How often do you have an alcoholic drink of any kind?' and 'On a day that you have alcoholic drinks, how many "standard" drinks do you usually have?'. Hazardous-harmful alcohol use = Current drinker who usually consumes three or more (females) or five or more (males) drinks on a day when he or she consumes alcohol. LL/UL95\%Cl=lower/upper limits of 95 per cent confidence interval for the point estimate.

Source: NSW Health Surveys 1997 and 1998 (HOIST). Epidemiology and Surveillance Branch, NSW Department of Health.

cent or less among women born in China, Lebanon and India, to 30.5 per cent among the New Zealand-born.

\section{CONCLUSION}

Health promotion programs coordinated at the state level in the areas of physical activity, skin cancer control, nutrition, smoking and alcohol consumption aim to reduce the incidence of cancer and other major causes of morbidity and mortality in NSW. The Health of the People of New South Wales: Report of the Chief Health Officer, 2000 provides a means of monitoring progress towards achieving the intermediate outcomes of these programs: that is, the reduction of risk factors in the population. The Report presents data on trends in standard indicators that have been defined by experts in the field, and thus provide a means of comparing progress in NSW with that elsewhere in Australia.

\section{REFERENCES}

1. Australian Institute of Health and Welfare. Australia's health, 2000: the seventh biennial health report of the Australian Institute of Health and Welfare. Canberra: AIHW, 2000.

2. Nutbeam D. Health promotion effectiveness-the questions to be answered. The evidence of health promotion effectiveness. Shaping public health in a new Europe (Part 2). Brussels: European Commission, 2000.

3. NSW Department of Health. The health of the people of New South Wales: Report of the Chief Health Officer, 2000. Sydney: NSW Department of Health, 2000.

4. Mathers C, Vos T, Stevenson C. The burden of disease and injury in Australia. Canberra: Australian Institute of Health and Welfare, 1999.
5. Stephenson J, Bauman A, Armstrong T, Smith B and Bellew B. The costs of illness attributable to physical inactivity in Australia. Canberra: Commonwealth Department of Health and Aged Care and the Australian Sports Commission, 2000.

6. Armstrong T, Bauman A, and Davies J. Physical activity patterns of Australian adults: results of the 1999 National Physical Activity Survey. Canberra: Australian Institute of Health and Welfare, 2000; 13.

7. Harris E, Sainsbury P, Nutbeam D (editors). Perspectives on health inequity. Sydney: Australian Centre for Health Promotion, 1999.

8. DeVita VT, Hellman S, Rosenberg SA. Cancer. Principles and practice of oncology. Fifth edition. Philadelphia: Lippincott-Raven publishers, 1997.

9. NHMRC. The core food groups: scientific basis for developing education tools. Canberra: NHMRC, 1995.

10. Public Health Division. The health of the people of New South Wales: Report of the Chief Health Officer, 1997. Sydney: NSW Department of Health, 1997.

11. Skin cancer control strategic plan 2000-2003. Sydney: NSW Cancer Council, 2000.

12. English DR, Holman CDJ, Milne E, Winter MG, Hulse GK, et al. The quantification of drug caused morbidity and mortality in Australia 1995. Canberra: Commonwealth Department of Human Service and Health, 1995.

13. Schofield WN, Lovelace KS, McKenzie JE, Burns L. Self reported tobacco and alcohol use among NSW secondary school students. The 1996 Australian School Students Alcohol and Drugs Survey. Sydney: NSW Cancer Council and NSW Department of Health,1998.

14. Townsend J. Cigarette smoking by socioeconomic group, sex, and age: effects of price, income, and health publicity. BMJ 1994; 309: 923-927. 路 